\title{
Research on the Hydrodynamic Characteristics of Typical Encountering Flood in the Lower Han River, China
}

\author{
Yazi Zheng, Junhong Zhang ${ }^{*}$, Mingkun Sun, Futian Pang \\ College of Resources and Environmental Science, South-central University for Nationalities, Wuhan, \\ China 430074, Email:zjh411891611@163.com
}

Keywords: the lower Han River; encountering flood; backwater influence; hydrodynamic characteristics

Abstract. Han River is the largest tributary of the Yangtze River, the hydrodynamics characteristics in the lower Han River is under the influence of upstream flow and sediment discharge and the backwater level of Yangtze River. Based on the one-dimensional hydrodynamic mathematical model, the hydrodynamic characteristics in the lower Han River were simulated and analyzed. The results show that the hydrodynamic characteristics change significantly under the different combinations of stage-discharge in the downstream and upstream. On the one hand, when the autumn flood occurred in the Han River basin after the flood season in the Yangtze River, there will be a sharp increase of water surface gradients and flow velocity. On the other hand, there is also an obvious decrease of flow velocity and water surface gradients when the multi-year average discharge coupling with the high water level of Yangtze River. It should be highly attentive to the hydrodynamic characteristic variation with the different combinations of stage-discharge in the two rivers, which is adverse to the dike safety, channel erosion and the waterway maintenance along the channel of Han River.

\section{Introduction}

Han River is the longest branch of the middle Yangtze River, which originates from Shanxi Province and flows through Shanxi Province and Hubei Province, converging into Yangtze River in Wuhan at last, as shown in Fig.1. The lower Han River is from Nianpanshan to estuary, $409 \mathrm{~km}$ long, which is the typical meandering river channel. The change rules of the flood period of Han River are mainly identical to precipitation ones ${ }^{[1]}$ : in general, flood period is from May to October, and dry season is from December to February of the next year, the rest of months are the normal period. The change rules of Yangtze River ${ }^{[2]}$ : in general, flood period is from May to September, July and August is the major flood period. The statistical data from hydrology bureau showed that the autumn-flood in Han River occurs usually in September to October, and for this reason, the time of autumn-flood in Han River lags Yangtze River's, namely the autumn-flood in Han River always meets the fall back period of Yangtze River ${ }^{[3-4]}$.

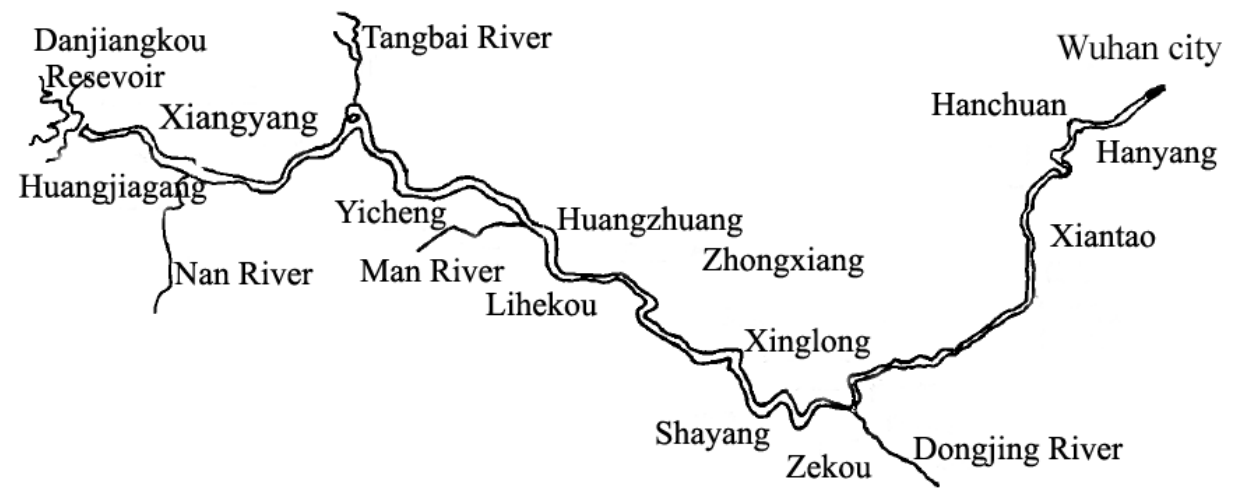

Fig. 1 Sketch of Han River in the lower reaches

When autumn-flood happens, on one hand, the flood of Yangtze River is declining, at the same time, the backwater interaction of Yangtze River is reducing and then the huge waterflow makes the flow velocity becomes larger at the estuary, leading the water level of Han River declined obviously. 
On the other hand, the huge waterflow after the autumn-flood and relative narrow watercourse leave watercourse in Han River intensely eroded and lots of bed material is carried into Yangtze River, leading the water level of Han River declined obviously again ${ }^{[5-6]}$. So the water level gap at the estuary of Han River is certainly obvious in the autumn-flood period.

\section{The study on hydrodynamic characteristics of encountering floods}

\section{The establishment of the one-dimensional hydrodynamic model}

This paper uses HEC-RAS to simulate the water level and flow change process from Xingou Station to estuary in the lower Han River. HEC-RAS here is a software that developed by the Hydrologic Engineering Center of United States Army Corps of Engineers to calculate flow line, which aims at the one-dimensional steady flow or unsteady flow hydraulic model ${ }^{[7]}$, mainly used in simulation analysis about the water flow situation in the open channel and identification of the flood plain areas. This paper does the research on the premise of steady flow in the channel of Han River.

\section{Hydrodynamic characteristics evolution under the different encountering floods}

In order to research the hydrodynamic characteristics under the different encountering floods in the lower Han River, the 5\% frequency flood, multi-year average discharge and the measured water level of Hankou Station corresponding with the former as the typical working conditions in model calculation $^{[8]}$. The calculation of working conditions is basically able to reflect the adverse flood control circumstance under typical flood encounter situation in the downstream watercourse of Han River, because the flow of autumn-flood in Han River is about the flow of $5 \%$ frequency flood ${ }^{[9]}$. As shown in Tab.1 the discharge ratio occurs a tremendous increase when autumn-flood happens, which is about $34 \%$ higher than the multi-year average discharge. However, there is not an obvious growth in water level at Hankou Station, which is because the water level of the middle Yangtze River falls back faster after flood period when the Three Gorges Reservoir is put into operation.

Tab.1 The different computing flood conditions in the lower Han River

\begin{tabular}{c|c|c|c}
\hline Computing conditions & $\begin{array}{c}\text { Discharge in Han River } \\
\left(\mathrm{m}^{3} / \mathrm{s}\right)\end{array}$ & discharge ratio (\%) & water level in Hankou $(\mathrm{m})$ \\
\hline 5\% frequency flood & 8300 & 44.1 & 17.73 \\
multi-year average & 1560 & 10.2 & 17.04 \\
discharge & & & \\
\hline
\end{tabular}

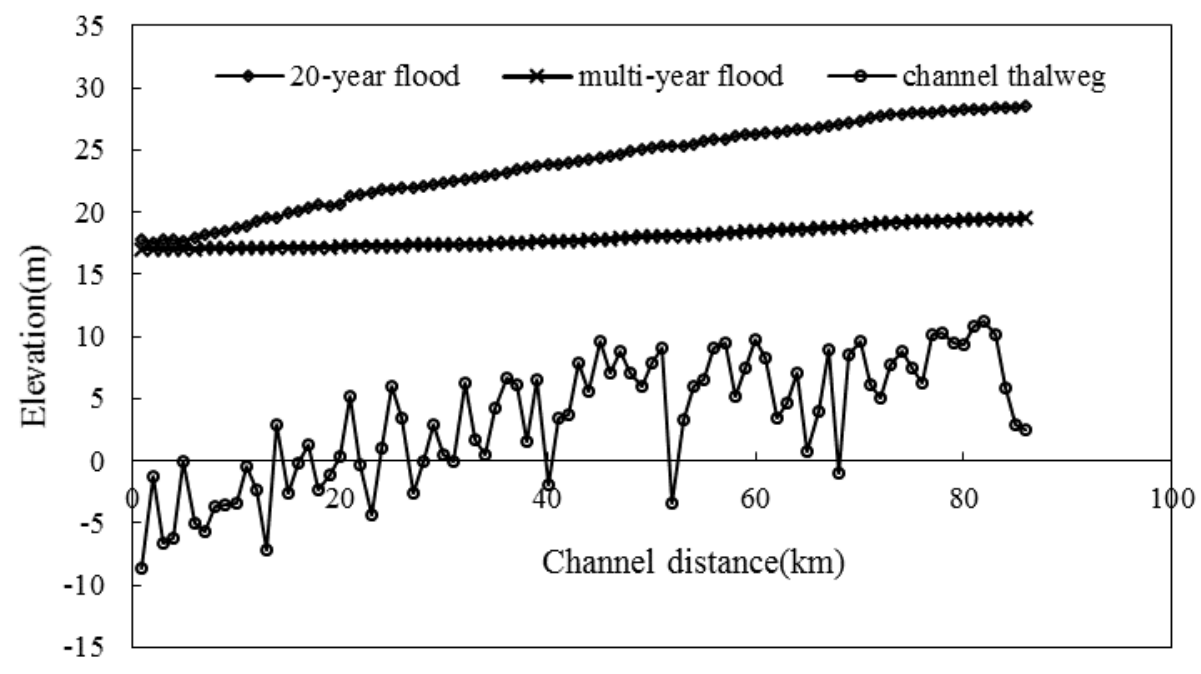

Fig.2 The change of water surface profile under computing conditions in the lower Han River

As shown in Fig.2, it is the calculated water surface profile. Water level amplitude is relatively gentle under multi-year average discharge and the gap of water level in the computing channel is 2.44m; there is sharp increase when the low water level encounters the autumn-flood of Han River 
basin, the gap of water level is up to $10.82 \mathrm{~m}$, which is larger than the ones of multi-year average discharge by 4 times, and the water surface gradient is increase obviously at the same time.

Under the different computing conditions, the mean velocity along the river has an obvious change with the water level. As shown in Fig.3, the maximum flow velocity at the watercourse from Xingou Station to estuary is $0.97 \mathrm{~m} / \mathrm{s}$ under the average annual flow; the minimum flow velocity is only $0.36 \mathrm{~m} / \mathrm{s}$, which has little variation along the channel. However, the maximum flow velocity is $3.93 \mathrm{~m} / \mathrm{s}$ and the minimum flow velocity is $1.22 \mathrm{~m} / \mathrm{s}$ under the $5 \%$ frequency flood, the flow velocity getting accelerated in the autumn-flood of the downstream of Han River with the water surging at the main channel in the lower Han River.

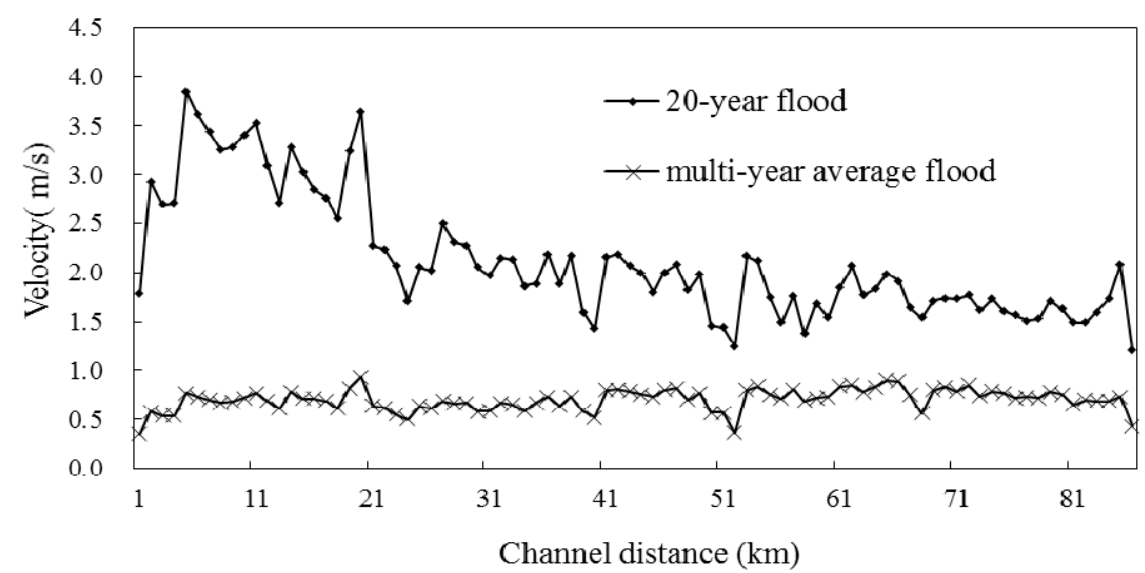

Fig.3 The change of mean velocity and talweg along the river under computing conditions in the lower Han River

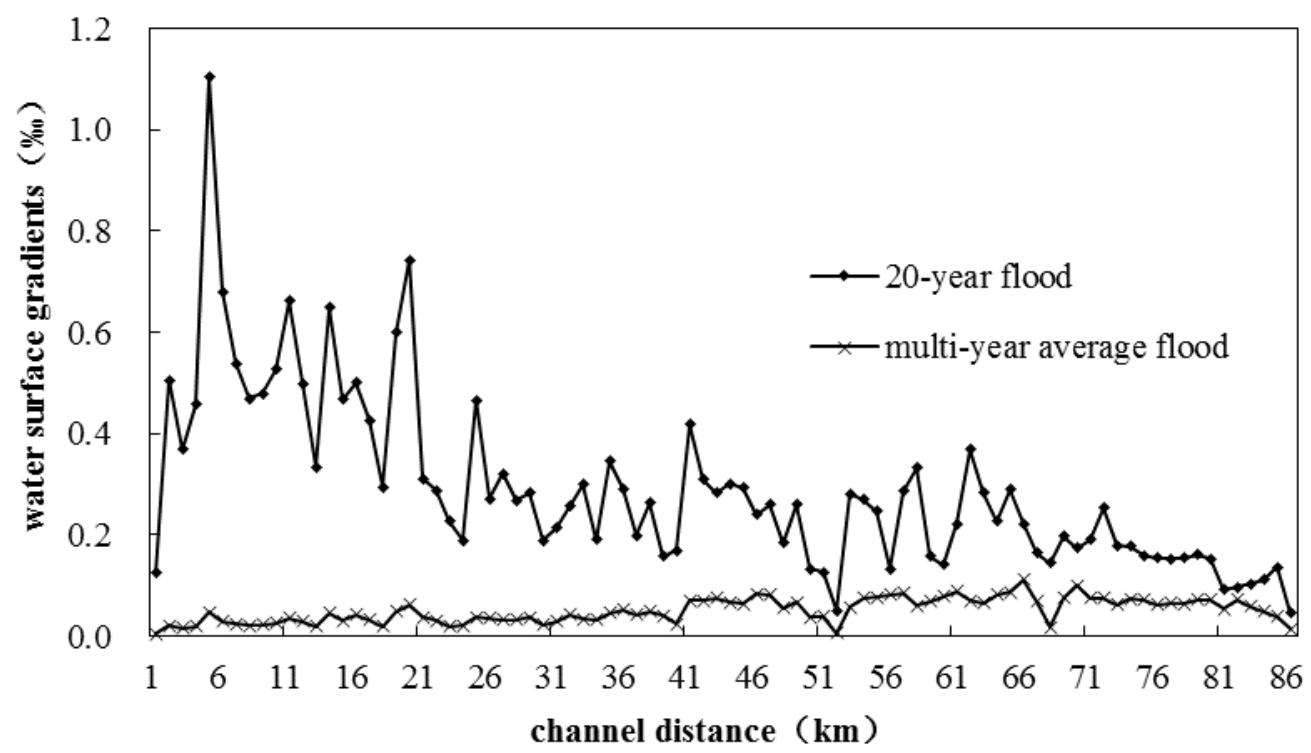

Fig.4 The curve of water surface gradient along the channel

Fig. 4 is the change of water surface gradient along the channel under the different computing conditions. As shown in the figure, the water surface gradient would increase greatly when Han River suffers the $5 \%$ frequency flood (autumn-flood). And the water surface gradient remains mostly above $0.6 \%$ within $20 \mathrm{~km}$ around the estuary. However, the situation about the average flood in many years is just opposite to the former: the closer the estuary is, the smaller the water surface is, and the stream gradient is always less than $0.2 \%$, which reflect that the channel in the lower Han River is obviously affected by the backwater level of Yangtze River under the mean annual discharge of Han River. 


\section{Conclusion}

This HEC-RAS software was used to simulate the flood process under different encountering floods in the lower Han River, and the simulating results were analyzed. The following conclusions have been drawn as follows:

(1)The hydrodynamics characteristics in the lower Han River are obviously affected by the flood from its upstream and the backwater level of Yangtze River. In addition, the duration of mean discharge is prolonged after the operation of the Three Gorges Dam. Therefore, the backwater level influence is much more serious under the multi-year discharge of Han River.

(2)The flow discharge in lower Han River increases sharply when the autumn-flood occurs. At the same time, it just is in the later period of flood of the middle Yangtze River. Therefore, the backwater effect of Yangtze River level to the lower Han River weakens gradually when the discharge ratio increase sharply. Under such a circumstances, the water surface gradient rises rapidly and flow velocity increases acutely, which brings huge threat to the dike safety in the lower Han River.

\section{Acknowledgements}

This work was financially supported by the Natural Science Foundation of Hubei Province, China (Grant No. BZY15026).

\section{References}

[1]Fan Bei lin,Wan Jian rong,Huang Yue. Influence of Water Transfer Project from South to North on middle and Lower reaches of Han River [J]. Journal of Yangtze River Scientific Research Institute, 2002, 19:21-24.

[2]Qiu Fenglian. Evolution analysis on downstream stretch of Han River [J]. Journal of Sediment Research, 1996, 6(2):101-104.

[3]Tong Hui, Yuan Jing, Chen Zefang. The channel evolution analysis of Han River estuary reaches [J]. Yangtze River, 2012, 43(supplement 1): 107-110.

[4]Chen Heping, Wu song. The hydrological impact of the South-north water diversion project and Three Gorges reservoir on the Wuhan reaches in the lower Han River [J]. Xinjiang nonferrous metals, 2013,(1):42-45.

[5]Qu Yueping, Huang Yong, He zhigao, Wu Guojun. The influence on water and sediment process in the lower Han River (from Xinglong to Hanchuan) due to the backwater effect of the Yangtze River [J]. China water transport, 2014, (11):61-64.

[6]Dai M.L., Ye L.L., Liu Y.Y. Study on encounter rules of floods from Han River and upper Yangtze River [J]. Yangtze River, 2012, 43(1):48-51.

[7]Hydrologic Engineering Center. HEC- RAS user's Manual version3.1 [Z].U.S.A.: U. S. Army Corps of Engineers, Davis, CA, 2002:3 17.

[8]Sun Zhaohua, Feng Qiufen, Han Jianqiao, Cao Qixin. Reasons for heavy deposition of sandbar at confluence of Yangtze River and Han River during autumn flood season of 2011[J]. Journal of hydroelectric engineering, 2014, 33(4): 111-117.

[9]Li Yitian, Deng Jinyun, Gan Fuwan. Threat on Bank of Han River due to the Impounding Water of TGP and Its Countermeasures [J]. Science \& Technology Review, 2007, 25(12):45-49. 